\title{
Understanding the Phylomorphological Implications of Pollinia from Dendrobium (Orchidaceae)
}

\author{
Bhupendra Chaudhary ${ }^{1,2^{*}}$, Pritam Chattopadhyay ${ }^{2}$, Neetu Verma ${ }^{2}$, Nirmalya Banerjee ${ }^{2}$ \\ ${ }^{1}$ School of Biotechnology, Gautam Buddha University, Greater Noida, India, ${ }^{2}$ Department of Botany, Visva-Bharati University, San- \\ tiniketan, India. \\ Email: "bhupendrach@gmail.com
}

Received April 18 ${ }^{\text {th }}$, 2012; revised May 14 ${ }^{\text {th }}, 2012$; accepted May 24 ${ }^{\text {th }}, 2012$

\begin{abstract}
We aim to evaluate the evolutionary trends of pollen ultra-structures and microstructures in the light of molecular phylogeny, and to test whether pollen micromorphology is a predictor of interspecific phylogenetic relationship or a consequence of ecological influences. Using scanning electron microscopy pollinia micromorphologies of 18 species of the genus Dendrobium were comprehensively examined. A phylogenetic tree from ribosomal-ITS2 sequences was constructed reflecting molecular phylogeny. In result, two major clusters were identified representing the sections Aporum, Formoase Dendrobium and Holochrysa. The section Dendrobium could be further classified, for the first time, into two clades sharing the same root of origin. Variations in the shape of pollinia were distinct and consistent constituting six novel groups. Other qualitative/quantitative keys to pollinia showed congruence with molecular phylogeny and supported the correlated evolution of these traits. Concurrently pollen sculpturing also showed large variation in exine morphology (rugular/psilate to psilate-scabrate/rugulate-scabrate) providing explicit clues for phylogenetic trend of exine evolution. For the characteristic sculpturing on the pollinia surface, a simple version of pre-pattern model is also hypothesized for deeper insight into pattern formation in other biological systems. Results indicated that distinct groups of Dendrobium species have parallel and independent evolution accompanied with genetic changes occurred during species diversification. Thus pollen micromorphology is a good candidate for inferring the genetic relationship at inter-specific level having phylogenetic implications even using abundant palynological records.
\end{abstract}

Keywords: Pollinia; Orchids; ITS2; Exine Morphology; Phylogeny

\section{Introduction}

Interesting patterns of species-level diversity in nature have been mostly revealed through many microstructures, those may be essential for elucidating relationship between acquired morphology and the endurance of flowering plants. In response to continuous selection pressure during species diversification, variations at interspecific level occur, and are responsible for varied phenotypes. The evolution of such morphological variability is mostly regulated by genetic components and their interactions with environment. A good example of such variability is the pollen grains. The type of pollen grain of any given taxon is characteristic and consistent suggesting for high degree of genetic regulation [1]. Therefore, study of differential pollen features from genetic perspective is essential to enhance our understanding of the ecological significance of variations in pollen morphologies. The acquired morphological features may either have phylogenetic implications or provide support for the eco-

\footnotetext{
${ }^{*}$ Corresponding author.
}

logical adaptation of the species. Variation in pollen grain features is a good example showing a range over three orders of magnitude [2], and may be good to study the influence of strong selection pressure during evolution. The evolution of pollen micromorphology is evident in all angiosperms, which is remarkably diverse, varying in size (from 20 - $250 \mu \mathrm{m}$ in diameter), in shape (conducive to wind capture), in weight, in hydration [2,3], in their pigments [4], in their nutritional content for pollinators [5], and in the patterns of their complex exine structures. These variations in pollen grains are also reported to be related to the evolved pollination strategies, however, with enormous interspecific variability. Pollen characters have frequently been observed to assess structural diversity [2,3], and also for their usefulness defining evolutionary trends in plant families such as Araceae [6], Callitrichaceae [7,8], Hydrocharitaceae [9], Fabaceae [10], Scrophulariaceae [11], and Orchidaceae [12-14].

Among flowering plants, the family Orchidaceae is the largest with more than 2500 reported species [13,15], and is known for its enormous diversity in pollen morphology 
[14]. The diversity has been observed at different levels: variability in packing of pollen in pollinia, in pollen wall structure, and in pollen surface sculpturing [16]. Hence, the structure and shape of pollinia have been used frequently for the classification orchids [17]. In particular, the exine micromorphology has been frequently used as reference character in taxonomical and phylogenetic analyses of angiosperms. Orchids, the exine characters show a remarkable diversity among closely related taxa [18]. In orchids, the exine characters were observed to be highly variable. Therefore, it was concluded that pollen features had produced phylogenetic information at least at the subtribal and generic levels [19]. There have been several attempts to correlate pollen surface sculpturing and pollen stratification with pollination strategies [20], and certain general patterns seem to be well established; such as elaborate pollen sculpturing is often correlated with entomophily, and psilate pollen grains may be characteristic for anemophilous or hypohydrophilous plants [9]. However, it may be more difficult to trace evolutionary tendencies within plant groups with similar pollination strategies. Clearly, an independently acquired knowledge of species relationships may help in elucidating correlations between pollen morphology and pollination strategies. In order, the palynological studies particularly in Orchidinae are scanty and least attempted in different genera from Indian subcontinent [21,22].

The genus Dendrobium is the second largest genus in Orchidinae, consisting of enormous pollen morphological diversity, and has been proved to be very useful and facile system to study the extent of genomic changes and adaptive radiance [23-25], with nearly 1184 reported species distributed throughout Indian sub-continent [26]. The cluster of mature pollen grains comprised a complex structure called pollinia having complete cell walls containing sperm cells inside. The pollinium cell walls are uniquely developed over time with constructions and elaborated surface layers, though vary subtly in surface stratification among species [27]. At maturity, the pollen surface has 1) an outer multilayered exine wall interrupted by openings called apertures; 2) an inner single or multilayered intine; and 3) a pollen coat, composed of lipids and proteins that fills the sculptured cavities of exine. The pollen heterogeneity of Dendrobium species may have promising systematic utility as proposed earlier for [28]. Since all living Dendrobium species are epiphytes, thus making it difficult to observe pollination and hence, information on pollination biology is relatively scarce.

The present study aims on the assessment of characteristic features of pollinia and pollen, their association, nature of apertures and sculpturing of the pollen surface of representative species of Dendrobium from India. This is to evaluate the revolution of pollen micromorphology with respect to its relationship with different allied the sections of the genus Dendrobium in the light of recent molecular phylogenetic reconstruction of these groups. In particular, we are interested in ascertaining whether the variation in pollen micromorphology reflects phylogenetic relationships among species or whether it may be significantly influenced by the striking difference in pollination ecology as also found among closely related species.

\section{Material and Methods}

\subsection{Collection of Plant Material}

For the present study, pollinia from 18 different species of the genus Dendrobium were collected from different parts of the Northern-East India. These species are $D$. anceps, D. chrysotoxum, D. densiflorum, D. thyrsiflorum, D. fimbriatum, D. moschatum, D. aphyllum, D. chrysanthum, D. devonianum, D. crepidatum, D. falconeri, D. nobile, D. parishii, D. ochreatum, D. primulinum, D. infundibulum, D. longicornu, and D. williamsonii which belong to different morphological the sections as defined earlier (Table 1). All authenticated plant materials were collected either under the supervision of Dr. U. C. Pradhan, an eminent Orchidologist from Kalimpong, West Bengal, India; or from Botanical Survey of India, Shillong as mentioned in Table 1. Pollinia were collected from 3 - 4 days old flowers from the orchidarium, and in replicates of two to six individuals per species as per the availability.

\subsection{Light Microscope (LM) Study}

Five pollinia of each species were measured three times observing shape, pollinia length and breadth recorded digitally with the help of a stereoscopic microscope (Hund WETZLAR 1021471) with epielumination (Hund WETZLAR FLQ 150). To study the pollens, pollinia were placed on a clean slide and crushed with help of a needle, and then observed under Leica DM 2500 microscope and measurements were recorded digitally at $40 \times$ of magnification using Leica QUIN-8 software. Measurements were also recorded for length and width of pollinaria, pollen-tetrad and polar and equatorial axes of pollen. Total 18 pollens were studied for each individual species and standard deviation is calculated. Pollen shape was determined by calculating the value of length of polar axis or length of equatorial axis.

\subsection{Scanning Electron Microscope (SEM) Study}

For SEM study, the dissected pollinia were directly mounted on copper stubs using double side sticky tape. The specimens were then sputter coated with gold-palladium alloy. These were examined and photographed under JEOL-35 JSM CF scanning electron microscope at an acelerating voltage of $15 \mathrm{kv}$ to study the pollinium surface 
Table 1. Combined list of Dendrobium species classified into different morphological characteristics based on the sections [31]. The site of collection is also shown for the investigated species along with the GenBank accession numbers of rDNA ITS2 sequences.

\begin{tabular}{|c|c|c|c|c|}
\hline Section & Sr. No. & Dendrobium spp. & Collected from & rITS 2 seqn. derieved from \\
\hline \multirow[t]{2}{*}{ Aporum ${ }^{\mathrm{i}, \mathrm{ii}}$} & 1 & D. anceps & Botanical Garden, Shilong & gb|HM054547.1 \\
\hline & 2 & D. chrysotoxum & U. C. Pradhan, Kalimpong & gi|211907904 \\
\hline \multirow[t]{2}{*}{ Densilora ${ }^{\mathrm{i}} /$ Callista $^{\mathrm{ii}}$} & 3 & D. densiflorum & U. C. Pradhan, Kalimpong & gb|AF314129.1 \\
\hline & 4 & D. thyrsiflorum & U. C. Pradhan, Kalimpong & gb|FJ384733.1 \\
\hline \multirow{5}{*}{$\begin{array}{l}\text { Holochrysa/Eugenanthee } \\
\text { subsection } \mathrm{I}^{\mathrm{ii}}\end{array}$} & 5 & D. fimbriatum & Botanical Garden, Shilong & gb|EU003116.1 \\
\hline & 6 & D. moschatum & Botanical Garden, Shilong & gb|AF314137.1 \\
\hline & 7 & D. aphyllum & U. C. Pradhan, Kalimpong & gb|EU840691.1 \\
\hline & 8 & D. chrysanthum & U. C. Pradhan, Kalimpong & gb|AF355572.1 \\
\hline & 9 & D. clavatum & Botanical Garden, Shilong & gb|EU121419.1 \\
\hline \multirow{7}{*}{$\begin{array}{l}\text { Dendrobium }{ }^{\mathrm{i}} / \text { Eugenanthee } \\
\text { subsection } \mathrm{II}^{\mathrm{i}}\end{array}$} & 10 & D. devonianum & Botanical Garden, Shilong & gb|AF311779.1 \\
\hline & 11 & D. falconeri & U. C. Pradhan, Kalimpong & gb|AF521610.1 \\
\hline & 12 & D. nobile & U. C. Pradhan, Kalimpong & gb|EF618732.1 \\
\hline & 13 & D. ochreatum & Botanical Garden, Shilong & gb|HM054720.1 \\
\hline & 14 & D. parishii & U. C. Pradhan, Kalimpong & gb|EU121417.1 \\
\hline & 15 & D. primulinum & Botanical Garden, Shilong & gb|AF362913.1 \\
\hline & 16 & D. infundibulum & Botanical Garden, Shilong & gb|HM054669.1 \\
\hline \multirow[t]{2}{*}{ Formosae $^{\mathrm{i}} / \mathrm{Nigrohirsutae}^{\mathrm{ii}}$} & 17 & D. longicornu & Botanical Garden, Shilong & gi|70795246 \\
\hline & 18 & D. williamsonii & U. C. Pradhan, Kalimpong & gb|FJ428220.1 \\
\hline
\end{tabular}

${ }^{\mathrm{i}}$ According to [15]; ${ }^{\text {ii }}$ According to [31].

structure, aperture, shapes, and exine sculpturing of pollen grain.

\subsection{Construction of Reference Phylogenetic Tree}

Ribosomal ITS sequences presently available for Dendrobium species, corresponding to those collected from NE-India, were obtained from sequence database. These sequences were then trimmed for ITS 2 as the nucleotide number for ITS 1, 5s rDNA, ITS 2, and 12s rDNA mentioned in the GeneBank format, using the web-tools provided with Enterz (Table 1). These authentic ITS2 sequences were first aligned using Bioedit and ClustalX programs where multiple alignment parameters were set at the default values. At this point if any ITS 2 sequence does not align with the other ITS 2 sequence of the same species, that may direct the phylogeny in wrong direction, and was eventually discarded. Subsequently, aligned sequences were exported to MrBayes and analyzed using NJ method using the model nucleotide p-distances which results into a consensus tree.

\subsection{Measurements and Statistical Analysis}

In the present study, we considered only those variables which could be measured directly. Therefore, we could consider only nine variables (pollinaria length (PoL); pollinaria width (PoW); Ratio of PoL and PoW, PoL/ PoW; tetrad length (TeL); tetrad width (TeW); Ratio of TeL and TeW, TeL/TeW; pollen polar axis (PpA); pollen equatorial axis (PeA); and ratio of $\mathrm{PpA}$ and $\mathrm{PeA}, \mathrm{PpA} /$
PeA measured up to $4^{\text {th }}$ decimal point of millimetre (mm). To represent the variability of all studied species, six variables were used to perform multivariate analyses using R-programme package. Principal component analyses (PCA) was carried out using the matrix of basic data set.

\section{Results and Discussion}

\subsection{Genetic Diversity in Dendrobium Species}

The genetic relationship among Dendrobium species was estimated using ribosomal DNA ITS2 region sequences, as this region exhibited higher level of sequence divergence than that of ITS1 or 5.8S rRNA regions. Moreover, the ITS2 sequences have earlier been proven to be appropriate molecular markers for differentiating orchid and other plant species $[24,29,30]$. Among the investigated species, the ITS2 sequences were available for all 18 species (GenBank accession numbers of sequences are listed in Table 1), and have been used to elucidate a phylogenetic tree treated as reference tree for the present investigation (Figure 1). In this analysis, two major clusters were observed from representative species of each morphological the section, based on important vegetative and floral characters (Table 1) [31]. In the first cluster, the single representative species, $D$. anceps grouped discretely as a member of the section Aporum (Table 1). $D$. williamsonii, $D$. longicornu, and $D$. infundibulum grouped together (members of the section Formosae; earlier known as Nigrohirsutae) with close proximity to the section Aporum, much similar to the division of morphological 


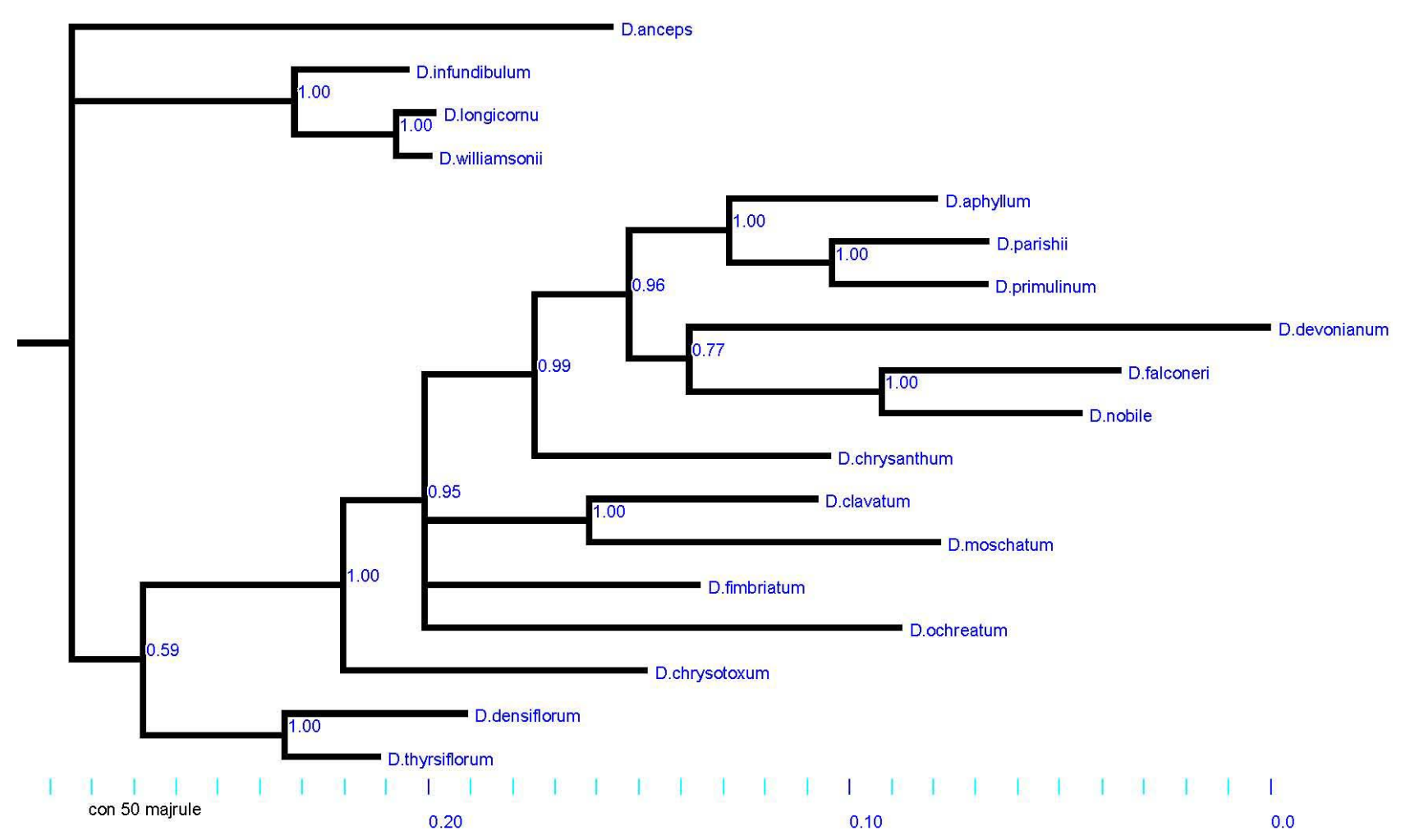

Figure 1. A reference phylogenetic tree derived from rDNA ITS 2 sequences of 18 species of Dendrobium. The length of ITS2 regions was 409 - 610 bp long and is highly conserved among the studied species.

the sections. The second cluster comprised with two distinct groups distinguished as the sections Dendrobium and Holochrysa. Interestingly both these the sections, have a common root of origin (Figure 1), as classified earlier in the section Eudendrobium [32]. Pradhan (1979) [15] also proposed analogous phylogenetic groups, Eugenanthae and Callista, largely represented by morphological characteristics. It was evident from rITS based phylogenetic tree (Figure 1), that the contemporary the sections Dendrobium and Holochrysa had comparable candidate species, distinctly divided earlier into subthe sections I and II under the section Eugenanthae by Pradhan (1979) [15]. Similarly, the section Callista has been reclassified as the section Densiflora [31]. However, present study showed certain prominent features in the phylogeny, which will help in understanding the origin and relationship of investigated species belonging to different morphological the sections.

One major group of investigated species constituted the section Dendrobium that could easily be classified into two clades having; $D$. aphyllum, D. parishii and $D$. primulinum in Clade 1 , and $D$. devonianum, $D$. falconeri and $D$. nobile in Clade 2 sharing the same root of origin (Figure 1). However, D. chrysanthum has been grouped as an out-group to Clade1 and Clade2; thus having significant genetic variation with other species of the section Dendrobium. This data suggest the parallel and independent evolution of distinct groups of Dendrobium species. Moreover, D. clavatum, D. moschatum and D. fimbriatum were grouped together in the section Holochrysa (Figure 1). However, $D$. ochreatum that was a defined member of the section Dendrobium earlier, exhibited more genetic relationship with the members of the section Holochrysa. This data may suggest the repositioning of this species within the section Holochrysa. However, a comprehendsive analysis of previously used morphological parameters is essential. Also, D. chrysotoxum was phylogenetically related as an out-group to the sections Dendrobium and Holochrysa; and supported its position in an outgroup the section Densiflora. This species was a defined member of the section Densiflora, that has been characterized earlier on the basis of morphological traits. However, it shared a different root of origin with $D$. densiflorum and $D$. thrysiflorum, the other member species of the section Densiflora (Figure 1). Such ambiguity may be argued as the latter showed a poor node value on the phylogenetic tree supporting the hypothesis of incorporation of $D$. chrysotoxum in the section Densiflora (Figure 1). Further genetic analyses of more species may be added to this outgroup the section facilitating its authentication. Thus the earlier morphological the sections [15,31], showed significant congruence with ITS2 based reference phylogram in the present study with some rearrangement of species and phyolgenetic relationships of Dendrobiinae 
elucidated earlier [24,25].

\subsection{Structural Diversity in Pollinia from Dendrobium spp.}

Pollinia morphology - the Dendrobium system represented by diversified members has got enormous potential to merge the understanding of cell biology with immense evolutionary diversity patterns. A good example is the pollinium, which is an aggregation of pollen grains into small masses. The SEM of pollinia from all investigated Dendrobium species were observed in multiple accession to normalize the intra-specific variations and showed remarkable variation in the morphology. The pollinium morphology in any particular the section was discrete in shape and colour across members. It was fusiform, slightly curved or comma shaped, with the inside surface slightly flattened. In most species, the two parts of each pair which cling together, are approximately of the same size (Figure 2). The pollinia length varied significantly among different the sections ranging from 0.74 $\mu \mathrm{m}$ to $2.75 \mu \mathrm{m}$ with an average of $1.67 \mu \mathrm{m}$. D. infundibulum (member of the section Formosae) had the largest pollinium size, whereas $D$. anceps (member of the section Aporum) had the smallest pollinium size (Figure 2, Table 2). In Dendrobium species, the pollinium has multiples of four-cell pollen clustered as bi-lobed, mostly smooth and kidney shaped, however with marked variations. The most precise pollinium shapes could be revealed through stereoscopic light microscopy having epillumination under $10 \times$ magnification because pollinium was light opaque and big enough to study under compound microscope. However, under SEM studies distortion of the pollinium shape was observed to be very common across species and this may be due to the applied vacuum pressure during sample preparation. The variations in the shapes were distinct and consistent among investigated species and are summarized below.

Group 1: Heart shape was observed in $D$. anceps, the only investigated member from the section Aporum (Figure 2). The two parts were closely attached to each other throughout the length without having any distinction of lobes. Exine morphology was observed to be of rugular type.

Group 2: Spindle shape was observed in $D$. infundibulum, D. longicornu and $D$. williamsonii, the representative members of the section Formosae. (Figure 2). The two parts were only attached at the upper region and the lobes were distinct. The adjacent inner lobes were longer than the outer lobes which were characteristic of this the section. Exine morphology was observed to be of rugular type (higher magnification could not show due to lack of clarity).

Group 3: Human foot-print shape was observed in $D$. aphyllum, D. chrysanthum, and D. primulinum, the representative members of the section Dendrobium (Figure 2). The two parts were attached utmost at the middle and basal regions and the lobes were distinct; whereas at the upper region the adjacent inner lobes depart making a characteristic toe shape. Exine morphology was observed to be of psilate type.

Group 4: Triangular shape was observed to be the characteristics of $D$. falconari and D. nobile, the representative members of the section Dendrobium (Figure 2). The two parts were variable as and closely attached, and widely spreaded in $D$. nobile and $D$. falconari, respectively. In $D$. nobile, the two lobes were marginally clear whereas in $D$. falconari lobes had a deep fissure separateing them through the entire length. Exine morphology was observed to be psilate-perforate type.

Group 5: Ovoid to circular shaped pollinium was observed in D. fimbriatum, D. clavatum, and D. moschatum, the representative members of the section Holochrysa (Figure 2). The two parts were attached at the uppermost and basal regions creating a stomatal-type opening. The two lobes were distinguished superficially. Exine morphology was observed to be psilate type.

Group 6: Bean shaped pollinia were observed in $D$. densiflorum and $D$. thyrsiflorum, the representative members of the section Densiflora (Figure 2). The two parts were attached throughout the length and two lobes were parallely distinct. Exine morphology was observed to be of psilate type.

Different pollinia shapes and wall patterns may be useful to identify representative members of different the sections, to establish phylogenetic relationship and in their taxonomic classification [13,33], though such studies are scarce in Dendrobiums. Earlier, the anatomy and development of orchid pollinia have received careful study with both SEM and tissue the sections with significant contributions on epidendroids by [18,34,35]; [14], and reviewed by [28]. Moreover, across orchid taxa, the pollinium had shown apparent evolutionary signatures, those may be important for pollen delivery and also for modulating the adhesion, hydration, and emergence of pollen tubes [36]. In the present study the role of pollinia morphology is highlighted inferring species relationship. The shape of pollinia varied into different species which were mostly in accordance with their respective the sections defined earlier [31]. Interestingly, shape of pollinia within the genus Dendrobium could illustrate the comparable species relationship as with ITS2 based reference phylogeny (Figure 1), discriminating species into defined the sections with least variation (Figure 2); whereas pollen micromorpholgical traits such as pollen shape, aperture type and number were observed to be incongruent with reference phylogeny. 

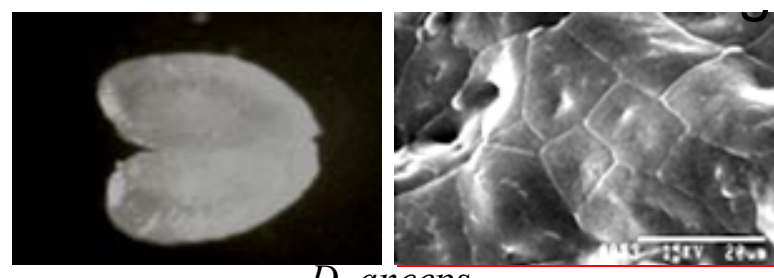

D. anceps

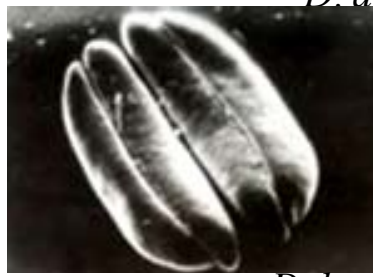

D. longicornu
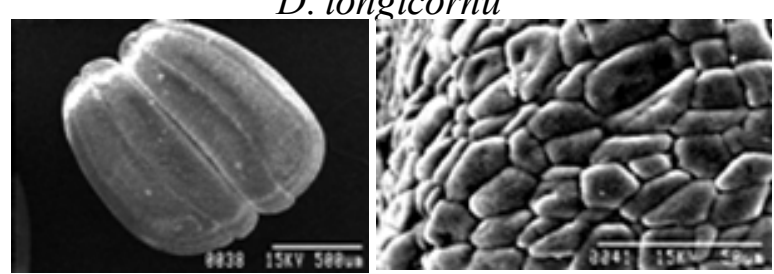

D. primulinum
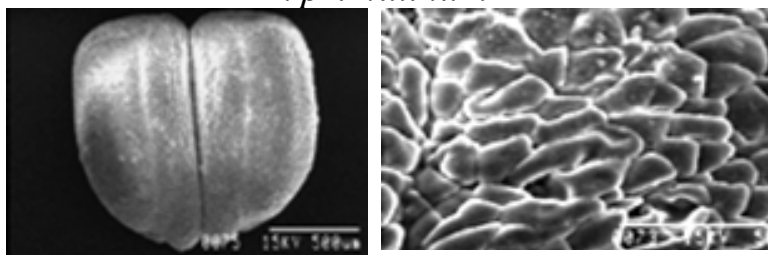

D. nobile

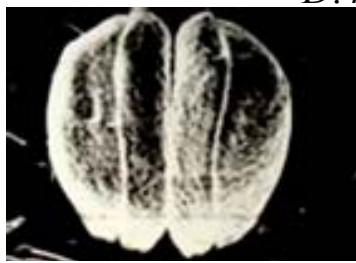

D. chrysanthum
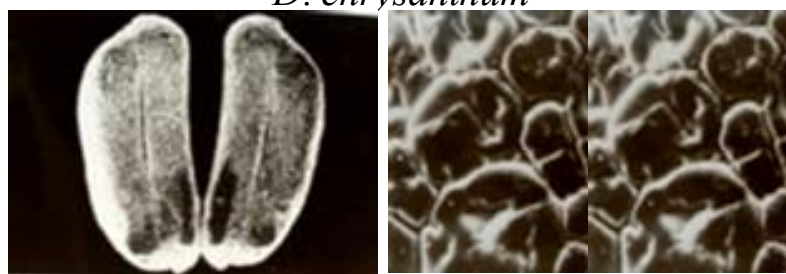

D. clavatum
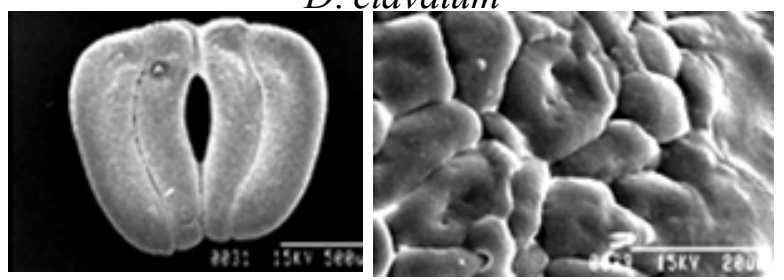

D. chrysotoxum

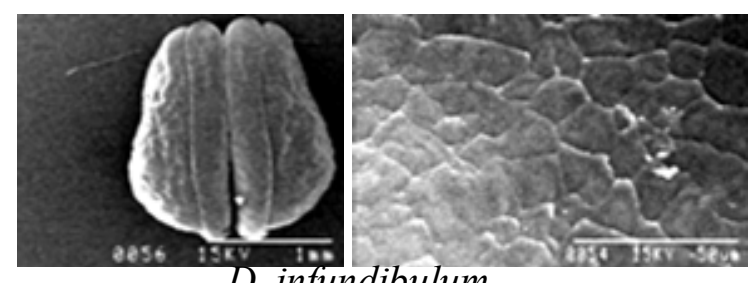

D. infundibulum
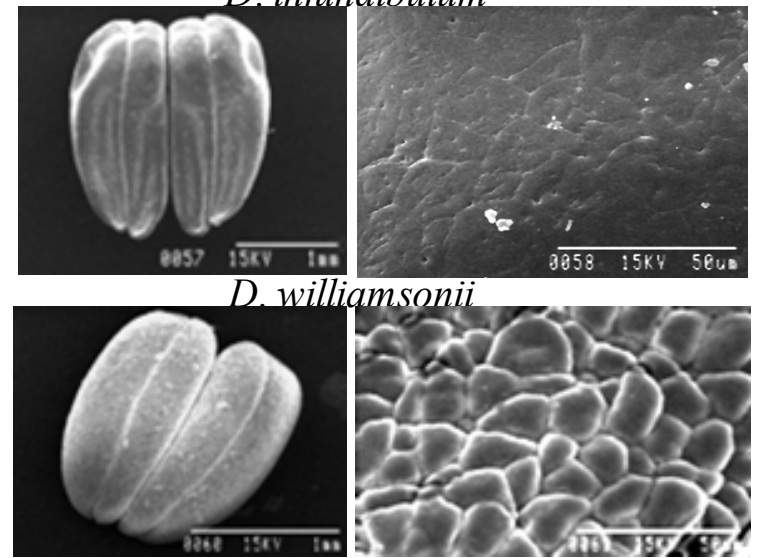

D. parishii
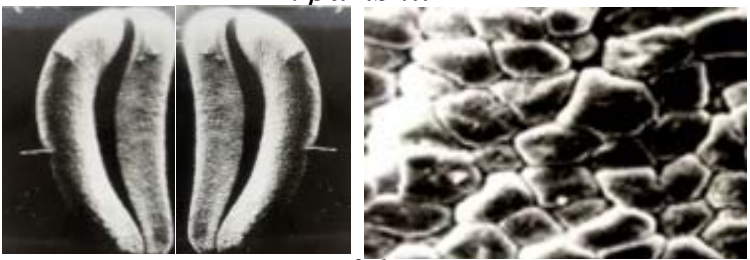

D. falconeri
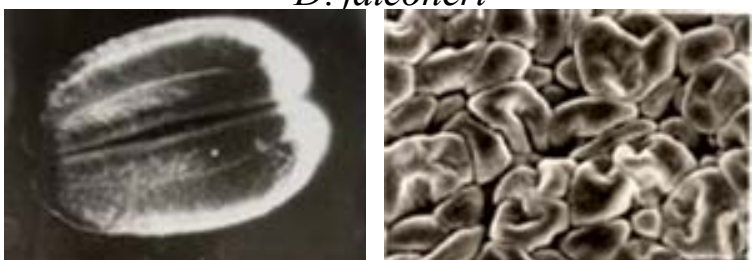

D. fimbriatum
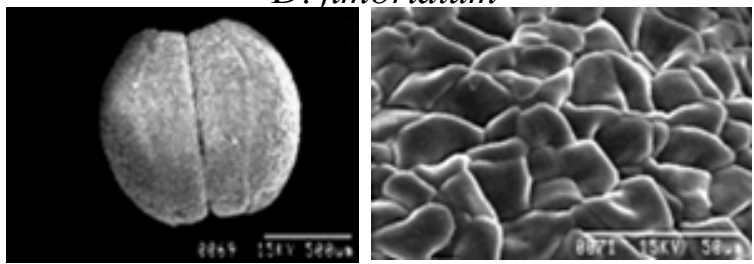

D. ochreatum

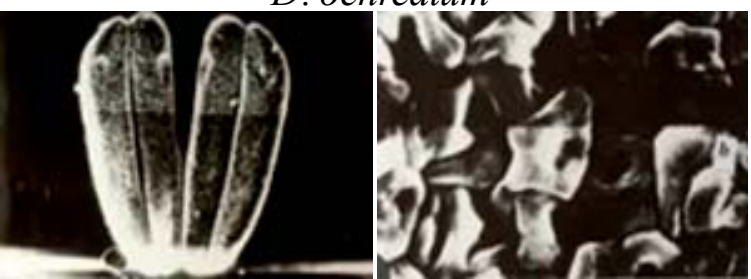

D. densiflorum

Figure 2. Structural diversity revealed through SEM in pollinia from all investigated species of Dendrobium. Different shapes have been observed ranging from fusiform to slightly curved or comma shaped, with the inside surface slightly flattened, having two almost same size parts of each pair clinging together. Magnified surface of pollen showed distinct types of exine morphology varying as rugular, psilate to psilate-scabrate, psilate-perforate and psilate types. The scale bars as per the SEM magnification are mentioned on each micrograph. 
Table 2. Morphometric analysis of Pollinia and pollen from different species of Dendrobium. The measurements are recorded in millimeters (mm).

\begin{tabular}{|c|c|c|c|c|c|c|c|c|c|}
\hline Species & PoL & PoW & PoL/PoW & TeL & TeW & TeL/TeW & PpA & $\operatorname{PeA}$ & PpA/PeA \\
\hline D. acceps & $0.74 \pm 0.03$ & $0.65 \pm 0.01$ & $0.695 \pm 0$ & $0.26 \pm 0.006$ & $0.21 \pm 0.006$ & $.23 \pm 0.02$ & $0.1 \pm 0.006$ & $2 \pm 0.006$ & \pm 0.01 \\
\hline D. aphyllum & $1.75 \pm 0.02$ & $1.25 \pm 0.03$ & $1.5 \pm 0.01$ & $0.362 \pm 0.008$ & $0.277 \pm 0.008$ & $1.306 \pm 0.03$ & $0.137 \pm 0.006$ & $0.181 \pm 0.01$ & $0.756 \pm 0.008$ \\
\hline D. chrysanthum & $1.58 \pm 0.02$ & $0.98 \pm 0.01$ & $1.28 \pm 0.02$ & $0.403 \pm 0.01$ & $0.218 \pm 0.006$ & $1.848 \pm 0.03$ & $0.136 \pm 0.006$ & $0.186 \pm 0.01$ & $0.731 \pm 0.006$ \\
\hline D. chrysotoxum & $1.3 \pm 0.03$ & $1.2 \pm 0.03$ & $1.25 \pm 0.03$ & $0.365 \pm 0.008$ & $0.243 \pm 0.006$ & $1.502 \pm 0.04$ & $0.127 \pm 0.006$ & $0.167 \pm 0.008$ & $0.76 \pm 0.008$ \\
\hline D. densiflorum & $1.45 \pm 0.01$ & $1.3 \pm 0.04$ & $1.375 \pm 0.02$ & $0.296 \pm 0.006$ & $0.23 \pm 0.006$ & $1.286 \pm 0.02$ & $0.128 \pm 0.006$ & $0.16 \pm 0.008$ & $0.8 \pm 0.01$ \\
\hline D. devonianum & $1.35 \pm 0.01$ & $1.25 \pm 0.03$ & $1.3 \pm 0.01$ & $0.37 \pm 0.008$ & $0.273 \pm 0.008$ & $1.355 \pm 0.02$ & $0.128 \pm 0.006$ & $0.153 \pm 0.006$ & $0.836 \pm 0.01$ \\
\hline D. falconerii & $1.78 \pm 0.04$ & $1.38 \pm 0.04$ & $1.58 \pm 0.04$ & $0.361 \pm 0.008$ & $0.248 \pm 0.006$ & $1.455 \pm 0.02$ & $0.131 \pm 0.006$ & $0.15 \pm 0.006$ & $0.873 \pm 0.01$ \\
\hline D. fimbriatum & $1.67 \pm 0.05$ & $1.33 \pm 0.04$ & $1.5 \pm 0.01$ & $0.33 \pm 0.008$ & $0.295 \pm 0.008$ & $1.118 \pm 0.01$ & $0.152 \pm 0.008$ & $0.181 \pm 0.01$ & $0.839 \pm 0.01$ \\
\hline D. infundibulum & $2.75 \pm 0.05$ & $2.2 \pm 0.05$ & $2.475 \pm 0.04$ & $0.43 \pm 0.01$ & $0.28 \pm 0.008$ & $1.535 \pm 0.04$ & $0.16 \pm 0.01$ & $0.19 \pm 0.01$ & $0.842 \pm 0.01$ \\
\hline D. longicornu & $2.55 \pm 0.04$ & $2 \pm 0.05$ & $2.275 \pm 0.04$ & $0.372 \pm 0.008$ & $0.278 \pm 0.008$ & $1.338 \pm 0.03$ & $0.15 \pm 0.006$ & $0.206 \pm 0.01$ & $0.728 \pm 0.006$ \\
\hline D. moschatum & $1.65 \pm 0.05$ & $1.3 \pm 0.02$ & $1.475 \pm 0.02$ & $0.427 \pm 0.01$ & $0.251 \pm 0.008$ & $1.701 \pm 0.04$ & $0.155 \pm 0.008$ & $0.192 \pm 0.01$ & $0.807 \pm 0.01$ \\
\hline D. nobile & $1.75 \pm 0.03$ & $1.35 \pm 0.02$ & $1.55 \pm 0.04$ & $0.333 \pm 0.008$ & $0.26 \pm 0.008$ & $1.28 \pm 0.04$ & $0.146 \pm 0.006$ & $0.183 \pm 0.01$ & $0.797 \pm 0.008$ \\
\hline D. ochreatum & $1.25 \pm 0.02$ & $1.25 \pm 0.03$ & $1.25 \pm 0.04$ & $0.487 \pm 0.01$ & $0.322 \pm 0.01$ & $1.512 \pm 0.02$ & $0.17 \pm 0.01$ & $0.216 \pm 0.01$ & $0.787 \pm 0.008$ \\
\hline D. parishii & $1.53 \pm 0.02$ & $1.6 \pm 0.04$ & $1.565 \pm 0.03$ & $0.45 \pm 0.01$ & $0.343 \pm 0.01$ & $1.312 \pm 0.02$ & $0.157 \pm 0.008$ & $0.21 \pm 0.01$ & $0.748 \pm 0.006$ \\
\hline D. primulinum & $1.76 \pm 0.04$ & $1.25 \pm 0.03$ & $1.505 \pm 0.02$ & $0.465 \pm 0.01$ & $0.334 \pm 0.01$ & $1.392 \pm 0.02$ & $0.175 \pm 0.01$ & $0.201 \pm 0.01$ & $0.87 \pm 0.008$ \\
\hline D. thyrsiflorum & $1.44 \pm 0.03$ & $1.25 \pm 0.03$ & $1.345 \pm 0.02$ & $0.381 \pm 0.008$ & $0.341 \pm 0.01$ & $1.114 \pm 0.03$ & $0.183 \pm 0.01$ & $0.222 \pm 0.01$ & $0.824 \pm 0.01$ \\
\hline D. williumsonii & $2.45 \pm 0.04$ & $1.9 \pm 0.04$ & $2.175 \pm 0.02$ & $0.378 \pm 0.008$ & $0.278 \pm 0.008$ & $1.354 \pm 0.05$ & $0.135 \pm 0.006$ & $0.178 \pm 0.008$ & $0.758 \pm 0.008$ \\
\hline
\end{tabular}

\subsection{Pollen-Tetrad Micromorphology}

The LM study of pollinia revealed that the pollen grains were liberated as tetrad into two discrete types, and varied at inter-specific level irrespective to their the sections. The representative pollen grains were 1) the decussate type of tetrads that was most common and observed in the majority of investigated species, for example, $D$. fimbriatum and D. aphyllum; and 2) the T-shaped type that was observed in $D$. devonianum, and $D$. williamsonii (Figure 3). In all cases, the pollen tetrad appeared to be angular, tetrahedral to polygonal, and cohered with small, profuse exinal connections to make up the pollinium. These finding were in accordance with previous SEM study which focused on two Dendrobium species in the section Holochrysa, D. moschatum and D. gibsonii, mainly highlighting the exine sculpturing and striated surface perforations [21]. In the present study the tetrad types were mostly common among investigated species and thus considered unsuitable to be the distinguishing character in orchids.

\subsection{Pollen Micromorphometric Markers and Species Relationship}

The length of polar axis $(\mu \mathrm{m})$ and length of equatorial axis $(\mu \mathrm{m})$ ratio were calculated to determine the pollen shape. When the ratio $>1.33$ or ranges from $1.33-2.00$

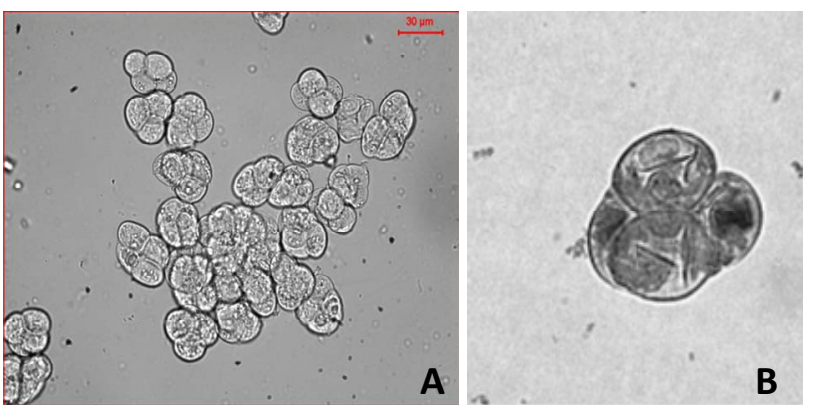

Figure 3. Light microscopy of two representative species showing two types of tetrad observed in species. (A) Decussate type pollen-tetrad, represented by $D$. aphyllum and (B) T-type pollen tetrad represented by $D$. williamsonii.

are considered as prolate shaped, and $<1.33$ considered as sub-prolate shaped [37]. Based on this calculation, pollen from all investigated species were observed to be sub-prolate shaped. However, the pollen apertures depicted a significant range of morphologies across the sections and differ considerably in type, shape and number. All investigated species were observed with colpate type of apertures, with an exception of $D$. williamsonii, where a colporate type of aperture was observed (Table 3) (figure not shown). The shapes of aperture were diverse irrespective to the morphological the sections, for example, roundish in $D$. aphyllum and $D$. nobile; spindleshaped in D. chrysanthum, D. devonianum, and D. mo- 
Table 3. Pollen micromorphology in representative species from different sections.

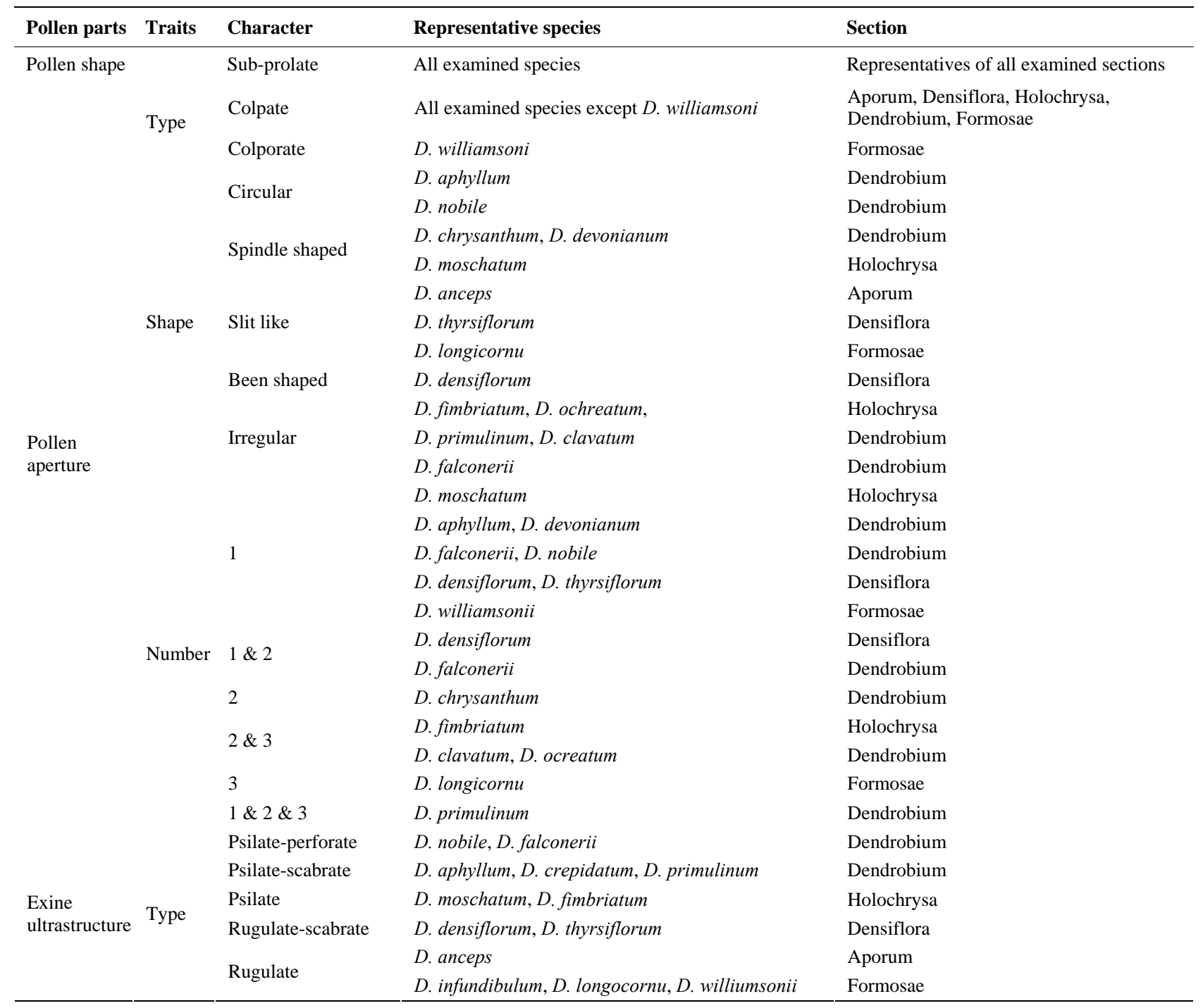

schatum; elongate and narrow shaped in D. longicornu and $D$. thyrsiflorum. However, the apertures were circular with elongated and narrow furrows in $D$. williamsonii; kidney shaped apertures in $D$. densiflorum; and irregular pattern was observed in $D$. clavatum, $D$. falconeri, $D$. fimbriatum, D. ochreatum, and D. primulinum (Table 3). Based on the number of apertures, different species could again be classified into 1) mono-aperturate species such as $D$. aphyllum, $D$. densiflorum, $D$. devonianum, $D$. falconeri, $D$. moschatum, D. nobile, D. thyrsiflorum, and $D$. williamsonii; 2) mono- and bi-aperturate species such as $D$. densiflorum, and D. falconeri; 3) bi-aperturate species such as $D$. chrysanthum, 5 bi- and tri-apertures species such as D. clavatum, $D$. fimbriatum, and D. ochreatum; 5) tri-aperturate species such as $D$. longicornu and 6) mono-, bi-, and tri-aperturate species such as $D$. primulinum (Table 3). Besides these, other important palynological parameters were also analysed to understand the signifi- cance of morphometric variability.

To determine the variability across investigated species, box plot analyses were performed for traits such as PoL, PoW, ratio of PoL/PoW, TeL, TeW, ratio of TeL/ TeW, PpA, PeA and ratio of PpA/PeA (Figure 4(a)). It was evident that the variability is distinct in pollen length with considerable overlapping among species, whereas pollen polar axis exhibited minimum variation (Figure 4(a)). From box plot analyses, minimum and maximum pollen lengths among investigated species were observed in $D$. anceps and $D$. infundibulum, respectively. Other significantly variable parameters were ratios of $\mathrm{PoL} / \mathrm{PoW}$ and TeL/TeW. Similarly, the pollen length was observed minimum and maximum in $D$. anceps and $D$. infundibulum, respectively. However, minimum and maximum ratios of $\mathrm{TeL} / \mathrm{TeW}$ were examined in $D$. thrysiflorum and D. chrysanthum, respectively (Figure 4(a)). Pridgeon (1999) [28] studied the orchid palynology and suggested 


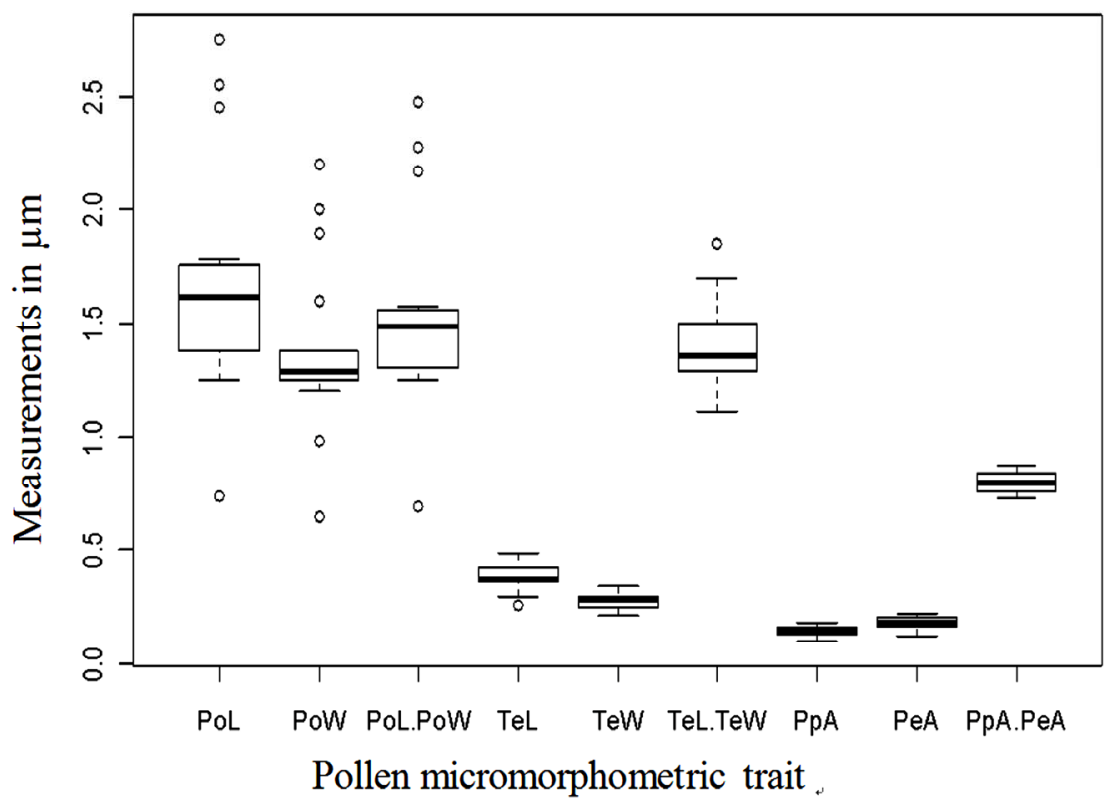

(a)

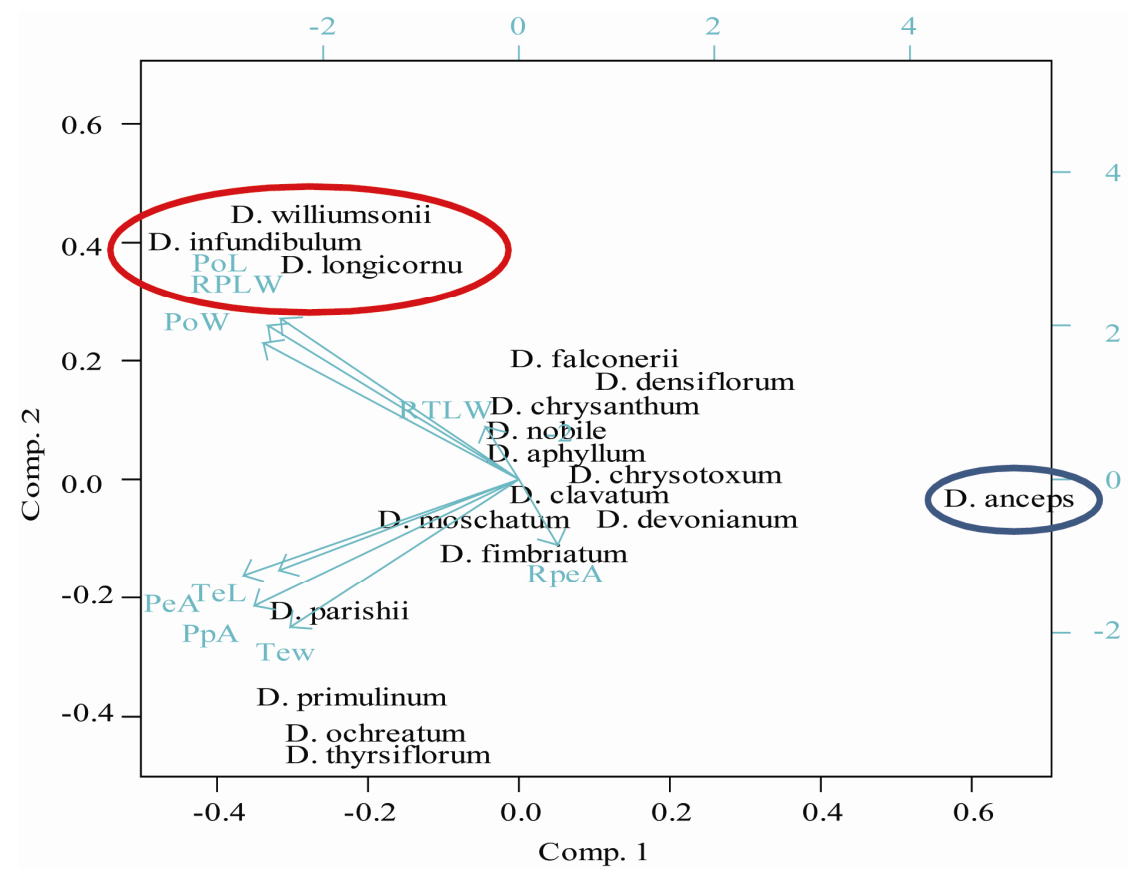

(b)

Figure 4. Measurements of different pollen morphometric markers and their role in the assessment of species relationship. (a) Box plot analyses of different pollen traits representing the variability across investigated species; (b) PCA analysis of investigated species with 9 pollen micromorphometric variables.

that the pollen heterogeneity of Orchidaceae may have promising systematic utility. The suggested pollen heterogeneity was well reflected in the present study through boxplot analysis where at inter-specific level, the pollen length varied maximum and pollen polar axis varied minimum. However, the phylogenetic relationships established, based on these pollen traits, showed high incongruence with ITS2 based reference phylogeny. It could be the reason that except pollen length, none of the variables showed significant distinction between species; and thus was not considered as distinguishing characters.

Further, PCA analysis of 18 species with 9 pollen micromorphometric variables showed total variability of $52.7 \%$ and $30.2 \%$ for the first two principal components, respectively. Based on clustering, only distantly related the sections such as Aporum and Formosae could be dis- 
tinguished from other the sections (Figure 4(b)). However, members of the section Densiflora could not be segregated from the section Holochrysa and two clades of the section Dendrobium (Figure 4(b)). This observation was well supported by the poor percentage values of total variability shown by principal components. Therefore, it may be concluded that pollen micromorphometric parameters can elucidate the phylogeny only for selected the sections. The observed PCA results were in accordance with the Dendrobium classification, proposed earlier by Hooker (1890) [32] and later supported by Pradhan (1979) [15], where the sections Aporum and Nigrohirsutae (=Formosae) were closely related and easily distinguished from distantly related the sections like Callista (=Densiflora), Eugenanthae subthe section I (=Holochrysa) and Eugenanthae subthe section II Dendrobium those jointly constituted mono-the section Eudendrobium.

As noted elsewhere, the main limitation in recognizing a phylogenetic signal in pollen characters of orchids depends on the influence of ecological factors such as differences in pollination strategies, in spite of evolutionary affinities among taxa. An attempt to elucidate the relationship between spur length of orchid flowers and pollen ultrastrcuture had been made emphasizing its role in orchid pollination biology [38,39]. Since the species of Dendrobium are mostly epiphytic, the knowledge of pollination biology in this system is still limited. As observed in the present study, the pollen length was the most variable parameter among all pollen characters studied. Hence, to investigate the rationale behind such signifycant variation in pollen length (assuming that it is without any phylogenetic implications), an effort was made to correlate the pollen length with an ecologically important trait, spur-length, to reveal if both these traits have been evolved in response to ecological adaptation. In result, a significantly positive correlation $\left(\mathrm{R}^{2}=0.816\right)$ was observed between these two traits, highlighting the fact that the pollen morphometric traits are evolved more in response to ecological factors rather than in the course of species evolution (Figure 5).

\subsection{Exine Microstructure and Ultrastructure Have Phylogenetic Implications Rather than Ecological Influences}

The outer pollen wall called exine is structurally complex comprising several distinct layers with explicit organizational patterns. These extraordinary surface features are important in the elucidation of the origins of the morphological complexity and diversity that may be useful to understand the science of palynology and its role in genetic diversity. The SEM of exine showed extreme variations in the number, distribution, and surface architecture (Figure 2). Apertures were observed diverse within and among investigated species (Table 3). Most often the surface of

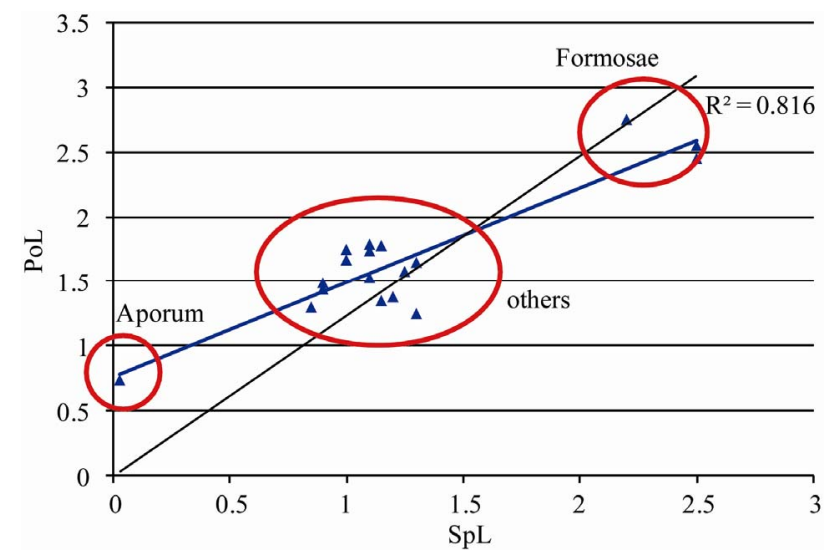

Figure 5. Regression analysis between spur length $(\mathrm{SpL})$ and pollinia length $(\mathrm{PoL})$ of the investigated species.

pollen was psilate and unsculptured. However, a gradual transition from psilate to rugular or scabrate pollen with several intermediate stages were observed (Figure 2, Table 3). D. anceps from the section Aporum and D. infundibulum, D. longicornu and $D$. williamsonii from the section Formosae exhibited rugular type of exine morphology, whereas $D$. chrysotoxum, $D$. densiflorum and $D$. thrysiflorum from the section Densiflorum showed rugulate-scabrate type of exine morphology (Figure 2, Table 3). Members of the section Dendrobium also showed psilate type of exine morphology with a range of variation. Species such as D. aphyllum and D. primulinum from the Clade 2 showed psilate-scabrate type while another group of species from Clade 2 showed psilate-perforate type of exine morphology (Figure 2, Table 3).

In orchid pollen grains, the ultrastructural features on the exine are initiated through the deposition of the polysaccharide material, called primexine. Subsequently, the germinal apertures are formed in positions on the surface through endoplasmic reticulum mediated blocking of the deposition of primexine precursor [40]. However, the pattern formation is still unclear, though clues are there for least characterized species-specific morphogens. Since Dendrobium species showed significant variation in surface stratification, general trends are needed to be established for pattern formation on pollen surface that may enhance our understanding for pattern formation process in biological systems. In this direction, a model to describe the structure-function inter-relation is proposed.

In the simplest version of pre-pattern model, at the margins of pollinia surface specialized producer (source) and receiver (sink) cells maintain the required morphogen concentration either at fixed levels or produced at a fixed rate during cell division [41]. We hypothesize that the "flux" (between source and sink) at the margins is more specified rather than the concentration. Therefore, for a single morphogen that is produced at the margins of a one-dimensional system working through diffusion into 
the regions and its subsequent decay, the steady-state morphogen concentration $(c)$ in scaled coordinates will be:

$$
c(\varepsilon)=(\mathrm{J} / \lambda) \varphi(\varepsilon)
$$

where, $\mathrm{J}=j \mathrm{~L} / \mathrm{D}$.

Thus the distribution is characterized by one dimensional parameter $\lambda$, that is the ratio of diffusion time scale and kinetic time scale, and a dimensional parameter $j$ defined by diffusion constant and decay rate in one-dimensional system length $\mathrm{L}$ (scaled as $1 / \mathrm{L}$ ). The former defines the shape function $\varphi$ at exponential terms determining the morphogen concentration in space. It is clear that for a fixed input flux $j$ both the amplitude and the shape of morphogen distribution depend on $L$ contributing to the characteristic sculpturing on the pollinia surface.

Pollen grains of orchidoids vary subtly in surface sculpture among species [18], but according to [42], no clear phylogenetic patterns are evident. [43] highlighted the role of ecological influences on the evolution of exine micromorphology of orchidinae along with other constraints applicable on flower topology under acquired pollination strategies. Parallel to these results, we observed that the exine ultrastructure or exine micromorphology has patterns those were in accordance with ITS2 based species relationship (Figure 2). These observations contradict with our earlier findings on seed ultrastructure showing incongruence with species phylogeny [44]. This may be for the reason that seed ultrastructures and pollen microfeatures in orchids are evolved under differential selection pressure and/or ecological influences.

It has been speculated that the prominent exine morphologies in Orchidoideae are evolved from primitive tectate-perforate to the contemporary intectate form, through disintegration from tectate-imperforate in Epidendroideae [16]. Such exine ultrastructures are certainly capable of developing an evolutionary hierarchy in orchids. For example, on the basis of exine ultrastructure members of the section Formosae may be considered as the most advanced because of their rugulate type and smooth topology. [34] explained that the smooth surface of advanced orchids is the result of the fusion of extosexine into a definite tectum; and progressive members may even lack detailed exine sculpturing [21]. The varied exine morphologies were well reflected among investigated species of Dendrobium (Figure 2), and thus highlight their importance in establishing the species relationship.

Certainly pollen exine sculpture patterns could produce phylogenetic information at the generic and subtribal levels [19]. However, in some orchid subtribes, such as in Disinae, pollen exine sculpture patterns were found to be highly variable allowing the distinction at inter-specific level or, as Oryciinae, it is substantially uniform for taxonomic resolution [19]. However, it is more difficult to trace evolutionary tendencies within plant groups having similar pollination strategies [11]. Nevertheless the present study suggests that this was not the case for the genus Dendrobium. All representatives from the sections Aporum and Formosae exhibited similar rugular type of exine morphology, and exhibited close relationship to the ITS2 based reference phylogenetic tree (Figure 1). In the reference phylogenetic tree, members of clade 1 and clade 2 of the section Dendrobium showed psilate type and psilate-scabrate type of exine morphology, respectively. The members of the sections Holochrysa and Densiflora were subsequent to the section Dendrobium where exine type was observed to be rugulate-scabrate type with several intermediate stages. Inspite of such large variation in exine morphology, a phylogenetic trend of exine evolution within the genus Dendrobium was apparent. These results are in parallel with the general topologies and evolutionary relationships among different species of Dendrobium proposed earlier by Chattopadhyay et al. (2010) [44] and [24] based on seed micromorphometry and ITS2 based parsimony analysis, respectively (Figure 1). These data will provide support to the hypothesis for the evolution of pollen ultra-features alongwith species evolution from different climatic regions during their adaptive diversification.

\section{Conclusion}

In the present study, details of exine structure for 18 Dendrobium species have been character-mapped onto the proposed reference molecular phylogeny. Many of all palynological traits investigated in comparison to reference phylogeny suggested the evolutionary trajectories of structural evolution of pollinia from Dendrobium species. The present study is the first to focus on the incorporation of pollen micromorphology data and ultrastructural features in a phylogenetic interpretation of the genus Dendrobium. There is, however, a fair possibility that these data may be sufficient only for limited systematic inquiries associated with the genus and its tribe, but the exine appears to be an excellent trait to incorporate into future cladistic analyses. Moreover, exine architecture correlates well with the various ecological characters evolved in response to pollination biology found within this genus.

\section{Acknowledgements}

This work was supported by Council of Scientific and Industrial Research, Government of India. We also thank Dr. S. J. Pukhan, Dr. A. Mao, and Dr. T. M. Hennuita of Botanical Survey of India, Dr. U. C. Pradhan, Orchid Research Group, India for their support in identification and collection of plant material. 


\section{REFERENCES}

[1] A. Hemsley, M. Collinson, B. Vincent, P. Griffiths and P. Jenkins, "Self-Assembly of Colloidal Units in Exine Development,” In: M. Harley, C. Morton and S. Blackmore, Eds., Pollen and Spores, Morphology and Biology, Royal Botanic Gardens, Kew, 2000, pp. 31-44.

[2] J. Muller, "Form and Function in Angiosperm Pollen," Annals of Missouri Botanical Garden, Vol. 66, No. 4, 1979, pp. 594-632. doi:10.2307/2398913

[3] K. J. Niklas, “The Aerodynamics of Wind Pollination," The Botanical Review, Vol. 51, No. 3, pp. 328-386. doi:10.1007/BF02861079

[4] K. Lunau, "The Ecology and Evolution of Visual Pollen Signals," Plant Systematics and Evolution, Vol. 222, No. 1-4, 2000, pp. 89-111. doi:10.1007/BF00984097

[5] T. H. Roulston and J. H. Cane, "Pollen Nutritional Content and Digestibility for Animals," Plant Systematics and Evolution, Vol. 222, No. 1-4, 2000, pp. 187-209. doi:10.1007/BF00984102

[6] M. Grayum, “Correlations between Pollination Biology and Pollen Morphology in the Araceae, with Some Implications for Angiosperm Evolution,” In: S. Blackmore and I. Ferguson, Eds., Pollen and Spores: Form and Function, Academic Press, London, 1986, pp. 313-327.

[7] J. Osborn and C. Philbrick, "Comparative Pollen Structure and Pollination Biology in the Callitrichaceae," Acta Botanica Gallica, Vol. 141, No. 2, 1994, pp. 257-266.

[8] J. Osborn, T. Taylor and E. Schneider, "Pollen Morphology and Ultrastructure of the Cabombaceae: Correlations with Pollination Biology,” American Journal of Botany, Vol. 78, No. 10, 1991, pp. 1367-1378. doi:10.2307/2445275

[9] N. Tanaka, K. Uehara and J. Murata, "Correlation between Pollen Morphology and Pollination Mechanisms in the Hydrocharitaceae,” Journal of Plant Research, Vol. 117, No. 4, 2004, pp. 265-276. doi:10.1007/s10265-004-0155-5

[10] I. Ferguson and J. Skvarla, "Pollen Morphology in Relation to Pollinators in Papilionoideae (Leguminosae)," Botanical Journal of Linnean Society, Vol. 84, No. 3, 1982, pp. 183-193. doi:10.1111/j.1095-8339.1982.tb00533.x

[11] H. Wang, R. Mill and S. Blackmore, "Pollen Morphology and Intrageneric Evolutionary Relationships in Some Chinese Species of Pedicularis (Scrophulariaceae)," Plant Systematics and Evolution, Vol. 237, No. 1-2, 2003, pp. 1-17. doi:10.1007/s00606-002-0188-y

[12] L. Averyanov, “A Review of the Genus Dactylorhiza,” In: J. Arditti, Ed., Orchid Biology, Reviews and Perspectives, Timber Press, Portland, 1990, pp. 159-206.

[13] R. Dressler, "Phylogeny and Classification of the Orchid Family,” Dioscorides Press, Portland, 1993.

[14] J. Freudenstein and F. Rasmussen, "Sectile Pollinia and Relationships in the Orchidaceae," Plant Systematics and Evolution, Vol. 205, No. 3-4, 1997, pp. 125-146. doi:10.1007/BF01464400

[15] U. Pradhan, "Indian Orchids: Guide to Identification and Culture,” Pradhan, Kalimpong, 1979.
[16] P. Burns-Balogh and M. Hesse, "Pollen Morphology of the Cypripedioid Orchids," Plant Systematics and Evolution, Vol. 158, No. 2-4, 1988, pp. 165-182. doi:10.1007/BF00936343

[17] F. Rasmussen, "The Development of Orchid Classification,” In: A. Pridgeon, P. Cribb, M. Chase and F. Rasmussen, Eds., Genera Orchidacearum, General introduction, Apostasioideae, Cypripedioideae, Oxford University Press, Oxford, 1999, pp. 3-12.

[18] R. Schill and W. Pfeiffer, "Untersuchungen an Orchideenpollinien unter Besonderer Berücksichtigung Ihrer Feinskulpturen,” Pollen et Spores, Vol. 19, 1977, pp. 105-118.

[19] P. Chesselet and H. Linder, "Pollen Morphology on the Diseae (Orchidoideae; Orchidaceae)," Grana, Vol. 32, No. 2, 1993, pp. 101-110. doi:10.1080/00173139309429460

[20] M. Hesse, "Pollen Wall Stratification and Pollination," Plant Systematics and Evolution, Vol. 222, No. 1-4, 2000, pp. 1-17. doi:10.1007/BF00984093

[21] C. Arora, "Status of Orchid Species in northwestern Himalayas and Their Conservation, with Special Reference to the Orchid-Rich-Belt in the Kumaon Hills,” In: S. Vij, Ed., Biology, Condervation and Culture of Orchids, EastWest Press, New Delhi, 1986, pp. 397-400.

[22] R. John and K. Jack, "Orchids: Sunset Books,” 3rd Edition, Little Brown \& Company, New York, 1998, pp. 11101.

[23] M. W. Chase, K. M. Cameron, R. L. Barrett and J. V. Freudenstein, "DNA Data and Orchidaceae Systematics: A New Phylogenetic Classification,” In: K. M. Dixon, S. P. Kell, R. L. Barrett and P. J. Cribb, Eds., Orchid Conservation, Natural History Publications, Kota Kinabalu, 2003, pp. 69-89.

[24] M. Clements, "Molecular Phylogenetic Systematics of the Dendrobiinae (Orchidaceae), with Emphasis on Dendrobium sect. Pedilonum," Telopea, Vol. 10, No. 1, 2003, pp. 247-298.

[25] T. Yukawa, H. Ohba, K. Cameron and M. Chase, "Chloroplast DNA Phylogeny of Subtribe Dendrobiinae (Orchidaceae): Insights from a Combined Analysis Based on rbcL Sequences and Restriction Site Variation," Journal of Plant Research, Vol. 109, No. 2, 1996, pp. 169-176. doi:10.1007/BF02344542

[26] I. Leitch, I. Kahandawala, J. Suda, L. Hanson, M. Ingrouille, M. Chase and M. Fay, "Genome Size Diversity in Orchids: Consequences and Evolution," Annals of Botany, Vol. 104, No. 3, 2009, pp. 469-481. doi:10.1093/aob/mcp003

[27] M. Barone Lumaga, S. Cozzolino and A. Kocyan, "Exine Micromorphology of Orchidinae (Orchidoideae, Orchidaceae): Phylogenetic Constraints or Ecological Influences?’ Annals of Botany, Vol. 98, No. 1, 2006, pp. 237-244. doi:10.1093/aob/mcl094

[28] A. Pridgeon, "Palynology,” In: A. Pridgeon, P. Cribb, M. Chase and F. Rasmussen, Eds., Genera Orchidacearum, Oxford University Press, Oxford, 1999, pp. 33-37.

[29] D. Lau, P. Shaw, J. Wang and P. But, “Authentication of Medicinal Dendrobium Species by the Internal Transcribed Spacer of Ribosomal DNA,” Planta Medica, Vol. 67, No. 5, 2001, pp. 456-460. doi:10.1055/s-2001-15818 
[30] Y. Zhang, P. But, Z. Wang and P. Shaw, "Current Approaches for the Authentication of Medicinal Dendrobium Speceis and Its Products,” Plant Genetic Resources, Vol. 3, No. 2, 2005, pp. 144-148. doi:10.1079/PGR200578

[31] H. Wood, “The Dendrobiums,” A.R.G. Ganter Verlag, Ruggell, 2006.

[32] J. Hooker, “Dendrobium,” Flora of British India, Vol. 5, 1890, pp. 710-752.

[33] W. Barthlott, "Morphologie der Samen von Orchideen im Hinblick auf Taxonomische und funktionelle Aspekte," Proceedings of Eighth World Orchid Conference, Frankfurt, 1976, pp. 444-445.

[34] N. Williams and C. Broome, "Scanning Electron Microscope Studies of Orchid Pollen,” American Orchid Society Bulletin, Vol. 45, 1976, pp. 699-707.

[35] E. Yeung, "Mechanisms of Pollen Aggregation into Pollinia in Epidendrum ibaguense (Orchidaceae)," Grana, Vol. 26, No. 1, 1987, pp. 47-52. doi:10.1080/00173138709428903

[36] A. Edlund, R. Swanson and D. Preuss, "Pollen and Stigma Structure and Function: The Role of Diversity in Pollination,” The Plant Cell, Vol. 16, Suppl. 1, 2004, pp. 84-97. doi:10.1105/tpc.015800

[37] G. Erdtman, "Pollen Walls and Angiosperm Phylogeny," Botaniska Notiser, Vol. 113, 1960, pp. 41-45.

[38] A. Pridgeon, P. Cribb, M. Chase and F. Rasmussen, "Genera Orchidacearum,” Oxford University Press, Oxford, 2001.
[39] N. van der Cingel, “An Atlas of Orchid Pollination,” Balkema Publishers, Rotterdam, 1995.

[40] J. Heslop-Harrison, "Wall Development within the Microspore Tetrad of Lilium longiflorum," Canadian Journal of Botany, Vol. 46, No. 10, 1968, pp. 1185-1192. doi:10.1139/b68-158

[41] H. Othmer, K. Painter, D. Umulis and C. Xue, “The Intersection of Theory and Application in Elucidating Pattern Formation in Developmental Biology," Mathematical Modelling of Natural Phenomenon, Vol. 4, No. 4, 2009, pp. 1-80.

[42] R. Bateman, P. Hollingsworth, J. Preston, L. Yi-Bo, A. Pridgeon and M. Chase, "Molecular Phylogenetics and Evolution of Orchidinae and Selected Habenariinae (Orchidaceae)," Botanical Journal of Linnean Society, Vol. 142, No. 1, 2003, pp. 1-40. doi:10.1046/j.1095-8339.2003.00157.x

[43] M. Lumga, S. Cozzolino and A. Kocyan, "Exine Micromorphology of Orchidinae (Orchidoideae, Orchidaceae): Phylogenetic Constrain or Ecological Influence?” Annals of Botany, Vol. 98, No. 1, 2006, pp. 237-244. doi:10.1093/aob/mcl094

[44] P. Chattopadhyay, N. Banerjee and B. Chaudhary, "Precise Seed Micromorphometric Markers as a Tool for Comparative Phylogeny of Dendrobium (Orchidaceae)," Floriculture and Ornamental Biotechnology, Vol. 4, 2010, pp. 36-44. 